\title{
Physicochemical Properties and Volumetric Change of Silicone/Bioactive Glass and Calcium Silicate-based Endodontic Sealers
}

\author{
Mario Tanomaru-Filbo, PbD, * Fernanda Ferrari Esteves Torres, MSc, * \\ Gisselle Moraima Chávez-Andrade, PbD, ${ }^{*}$ Madelise de Almeida, ${ }^{*}$ \\ Luciana Guilberme Navarro, DDS, * Liviu Steier, PbD, ${ }^{+}$ \\ and Juliane Maria Guerreiro-Tanomaru, $P b D^{*}$
}

\begin{abstract}
Introduction: This study evaluated setting time (ST), radiopacity, $\mathrm{pH}$, flow, solubility, and volumetric change (VC) of a silicone, gutta-percha, and bioactive glassbased sealer, GuttaFlow Bioseal (GFB), and a calcium silicate-based sealer, TotalFill BC Sealer (TFBC), in comparison with AH Plus. Methods: ST and flow were evaluated in accordance with the ISO 6876 Standard. $\mathrm{pH}$ was evaluated after different time intervals $(1,3,7$, 14,21 , and 28 days). Radiopacity was evaluated by radiographic analysis in millimeters of aluminum. Solubility was evaluated by means of mass loss (\%) after 7 and 30 days of immersion in distilled water. VC was evaluated by micro-computed tomography, by using cavities $3 \mathrm{~mm}$ deep and $1 \mathrm{~mm}$ in diameter in acrylic resin, filled with the materials. The materials were evaluated after setting and after 7 and 30 days of immersion in distilled water. The data were submitted to analysis of variance and Tukey statistical tests $(P<.05)$. Results: TFBC demonstrated the highest pH and solubility. GFB had the shortest ST, and lowest radiopacity and flow values. VC was similar for the sealers in both time intervals. Conclusions: TFBC presented the highest $\mathrm{pH}$ and solubility, but showed similar VC to GFB and AH Plus. GFB showed proper physicochemical properties. Micro-computed tomography complements the physicochemical analysis of endodontic sealers. (J Endod 2017;43:2097-2101)
\end{abstract}

\section{Key Words}

Micro-computed tomography, physicochemical properties, root canal sealer
$R_{p}^{o}$ ot canal sealers must Dresent physicochemical properties in accordance with the standards defined by the American Institute, American Dental Association (ADA) (1) International Organization for Standardization (2).

AH Plus (AHP) is a gold standard epoxy resin-based sealer that has been used in endodontic sealer evaluations (3) due its excellent physicochemical properties (4-8). EndoSequence and TotalFill BC Sealer (TFBC) are premixed, ready-for-use bioceramic endodontic sealers (9). These sealers are in accordance with ISO 6876 for most physicochemical properties and present favorable biological property (3). EndoSequence BC Sealer has $\mathrm{pH}$, flow, and dimensional stability in accordance with the ISO standards (10). TFBC has demonstrated cytocompatibility (11), bond strength $(12,13)$, and dentin penetrability (14). GuttaFlow Bioseal (GFB) is composed of gutta-percha, polydimethylsiloxane, platinum catalyzer, zirconium dioxide, and bioactive ceramic glass. GFB was developed to improve GuttaFlow bioactivity favoring the regeneration of apical tissues (15). GFB has shown low solubility and porosity, alkalization capacity (15), and dentin penetrability (4). Although GuttaFlow Bioseal has cytocompatibility, physicochemical evaluations are required to confirm its clinical application (16).

Micro-computed tomography (micro-CT) may be used for analyzing the physicochemical properties of endodontic sealers and provides qualitative or quantitative tridimensional analysis $(17,18)$. The use of micro-CT allows the volumetric analysis (in $\mathrm{mm}^{3}$ ) of materials, and is able to improve conventional tests (19-21). The conventional solubility test is performed by means of the difference in mass before and after immersion of the materials in distilled water for 24 hours; however, materials may present some type of disintegration during storage, or absorb water (22). Furthermore, the period of 24 hours may not provide information about material behavior over time. Therefore, micro-CT has been proposed to evaluate the volumetric change in endodontic materials, with possible correlation with solubility and dimensional change after different time intervals $(20,21)$, allowing better understanding of the dimensional behavior of the materials after longer periods (21).

From the *Department of Restorative Dentistry, Araraquara Dental School, São Paulo State University, Araraquara, São Paulo, Brazil; and ${ }^{\dagger}$ Warwick Medical School, The University of Warwick, Coventry, UK.

Address requests for reprints to Dr Mario Tanomaru-Filho, Araraquara Dental School, São Paulo State University - UNESP Department of Restorative Dentistry, Humaitá Street, 1680, 14801-903 Araraquara, SP, Brazil. E-mail address: tanomaru@uol.com.br

$0099-2399 / \$$ - see front matter

Copyright $\odot 2017$ American Association of Endodontists.

http://dx.doi.org/10.1016/j.joen.2017.07.005 
The development of new endodontic sealers and new tests may enhance evaluation and knowledge about the behavior of these materials. The aim of this study was to evaluate the physicochemical properties of a silicone, gutta-percha, and bioactive glass-based sealer (GFB) and a calcium silicate-based sealer (TFBC) in comparison with AHP, by using conventional tests and volumetric change using micro-CT.

\section{Materials and Methods}

The endodontic sealers used in this study and their respective manufacturers are described in Table 1.

\section{Physicochemical Properties: Conventional Methods}

Seting Time. Plaster molds measuring $10 \mathrm{~mm}$ in diameter and $1 \mathrm{~mm}$ high were used to fabricate specimens of each material $(n=6)$. Plaster molds were immersed in water for 24 hours at $37^{\circ} \mathrm{C}$, and then the cavities were filled with the material. Setting time (ST) was evaluated in accordance with the ISO 6876 (2). A Gilmore needle with mass of $100 \pm 0.5 \mathrm{~g}$ and diameter of $2.0 \pm 0.1 \mathrm{~mm}$ was used, supported on the sealer surface. The materials were kept in an oven at $37^{\circ} \mathrm{C}$ and $95 \%$ humidity. ST of the sealers was considered as the time when the marks of needle could not be observed on the sealer surface.

Radionacity. Specimens ( $n=5)$ measuring $10 \mathrm{~mm}$ in diameter by $1 \mathrm{~mm}$ thickness were made for each tested material. The radiopacity was evaluated according to Tanomaru-Filho et al (23). Each sample was positioned on 5 occlusal radiographic films (Insight-Kodak Comp, Rochester, NY) and exposed, along with an aluminum stepwedge with variable thickness (from 2 to $16 \mathrm{~mm}$, in 2-mm increments). An X-ray unit (Instrumentarium Dental, Tuusula, Finland) operating at $60 \mathrm{kV}$, $7 \mathrm{~mA}, 0.32$ pulses per second, and focus-film distance of $33 \mathrm{~cm}$ was used. The films were processed in a standard automatic processor (Dent-X 9000; Dent-X, Elmsford, NY). Radiographs were digitized, and the images were imported to the Image Tool 3.0 software (University of Texas Health Science Center at San Antonio [UTHSCSA], San Antonio, TX); an equal-density tool was used to identify equal-density areas in the radiographic images. Thus, the radiopacity of the evaluated sealers was estimated from the thickness of aluminum (in $\mathrm{mm}$ ) by using a conversion equation. The values recorded for each material were averaged to obtain a single value in $\mathrm{mm} \mathrm{Al}$.

Solubility. Based on a previous study (24), circular plastic molds measuring $1.5 \mathrm{~mm}$ high and $7.75 \mathrm{~mm}$ in diameter were placed on a glass plate covered with cellophane film. These molds were filled with each of the evaluated sealers $(n=6)$. A nylon thread was embedded in the fresh sealer mixture, and another glass plate covered with cellophane was placed over the mold. For TFBC that do require moisture for setting, 2 pieces of wet cloth were placed between the mold and the glass plates. This unit was kept at $37^{\circ} \mathrm{C}$ and $95 \%$ humidity for 3 times the duration of their setting time. The test specimens were removed from the molds and weighed on a precision balance (HM-200; A \& D Engineering, Inc., Bradford, MA). Then, they were placed in closed plastic flasks containing $7.5 \mathrm{~mL}$ of distilled and deionized water. The specimens were attached to the containers with nylon threads and kept in an oven at $37^{\circ} \mathrm{C}$ for 7 days. After this period, they were washed in distilled water, and placed in a dehumidifier. The mass was measured before and after the samples were immersed in distilled water, and every 24 hours thereafter, until the mass was stabilized. New samples were made and kept immersed in distilled water for 30 days. The loss of mass was expressed as a percentage of the original mass. In accordance with ISO and ANSI/ADA, the results must not exceed contraction of $1.0 \%$ or expansion of $0.1 \% \mathrm{pH}$.

$\mathrm{pH}$ polyethylene tubes (Embramed Ind. Com., São Paulo, SP, Brazil) measuring $10 \mathrm{~mm}$ length and $1.6 \mathrm{~mm}$ diameter were filled with freshly prepared samples of each material $(n=10)$. The tubes were immersed in plastic flasks containing $10 \mathrm{~mL}$ of deionized water. The flasks were closed and kept in an oven at $37^{\circ} \mathrm{C}$. $\mathrm{pH}$ measurements were performed after 1, 3, 7, 14, 21, and 28 days. The solution's pH was analyzed at each period using a previously calibrated digital $\mathrm{pH}$ meter (Digimed, São Paulo, Brazil). After each measurement (in triplicate), the mean $\mathrm{pH}$ of each group in each experimental period was calculated.

Flow. The flow test was conducted in accordance with ISO Standard 6876 (2). After manipulation of the sealer, $0.05 \mathrm{~mL}$ of the material was placed in the center of a glass plate using a graduated syringe $(n=10)$. At $180 \pm 5$ seconds after initiating the manipulation, another glass plate $(20 \mathrm{~g})$ was placed on the plate with the sealer, and a 100-gram weight was put on the top plate, and kept there for 10 minutes. After this period, the maximum and minimum diameters of the material on the glass plate were measured. When a difference of less than $1 \mathrm{~mm}$ between the diameters was observed, the mean value was recorded. A second evaluation was made by photographing the material on the plate alongside a millimeter ruler. The images obtained were evaluated using the Image Tool 3.0 software (UTHSCSA, San Antonio, TX) to obtain the area of flow of the material expressed in $\mathrm{mm}^{2}$, according to Tanomaru-Filho et al (23).

\section{Volumetric Change: Micro-Computed Tomography Analysis}

Volumetric change of the sealers was analyzed using micro-CT (Bruker-MicroCT, Kontich, Belgium). Transparent acrylic resinbased models were fabricated using metal molds with cavities measuring $3 \mathrm{~mm}$ deep and $1 \mathrm{~mm}$ in diameter $(n=6)$. The cavities were filled with each of the materials by a single operator, who was previously trained and calibrated. The samples were kept in an oven at $37^{\circ} \mathrm{C}$ and relative humidity for 3 times the duration of their ST. For TFBC setting, a piece of wet cloth was placed over the cavities.

TABLE 1. Endodontic Sealers and Their Manufacturers

\begin{tabular}{cccc}
\hline $\begin{array}{c}\text { Endodontic } \\
\text { sealer }\end{array}$ & $\begin{array}{c}\text { Lot number and } \\
\text { expiration date }\end{array}$ & Manufacturer & Composition \\
\hline $\begin{array}{c}\text { GuttaFlow } \\
\text { Bioseal (GFB) }\end{array}$ & G41719 2017-05 & Coltene/Whaledent, Altstatten, Switzerland & $\begin{array}{c}\text { Gutta-percha powder, polydimethylsiloxane, } \\
\text { platinum catalyst, zirconium dioxide, silver } \\
\text { (preservative), coloring, bioactive glass } \\
\text { ceramic }\end{array}$ \\
$\begin{array}{c}\text { TotalFill BC } \\
\text { Sealer (TFBC) }\end{array}$ & 14003 SP 2016-09 & $\begin{array}{c}\text { FKG Dentaire SA, La Chaux-de-Fonds, } \\
\text { Switzerland }\end{array}$ & $\begin{array}{c}\text { Zirconium oxide, calcium silicates, calcium } \\
\text { phosphate monobasic, calcium hydroxide, } \\
\text { filler and thickening agents }\end{array}$ \\
AH Plus (AHP) & 1401000822 2015-10 & $\begin{array}{c}\text { Dentsply DeTrey, Konstanz, Germany } \\
\text { Bisphenol A/F epoxy resin, calcium tungstate, } \\
\text { zirconium oxide, silica, iron oxide pigments } \\
\text { dibenzyldiamine, aminoadamantane, } \\
\text { silicone oil }\end{array}$ \\
\hline
\end{tabular}



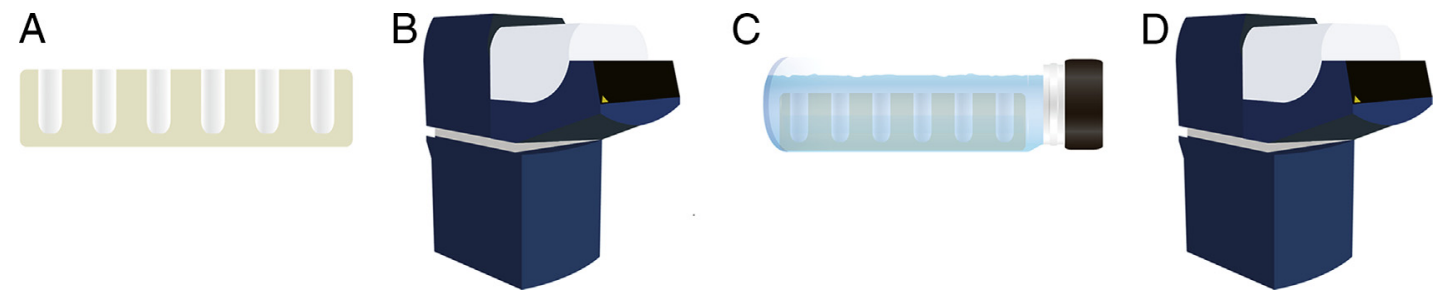

Figure 1. Schematic figure representing the volumetric change assessment. (A) Transparent acrylic resin-based models with cavities measuring $3 \mathrm{~mm}$ deep and $1 \mathrm{~mm}$ in diameter $(n=6)$ filled with the sealers. $(B)$ Micro-computed tomography $(C T)$ scan after setting time. $(C)$ Samples immersed in distilled water during the experimental time intervals. $(D)$ Micro-CT scan after 7 and 30 days.

Then, the samples were scanned by micro-CT (Bruker-MicroCT). The samples were immersed in distilled water for 7 and 30 days and they were scanned again after these experimental time intervals. The scanning procedure was performed using $50 \mathrm{kV} \mathrm{X-ray} \mathrm{tube} \mathrm{voltages} \mathrm{and}$ $500 \mu \mathrm{A}$ anode current; aluminum filter of 0.5 ; isotropic voxel of $18 \mu \mathrm{m}$; and a $360^{\circ}$ evolution cycle. The images were used for quantitative analysis of the samples, allowing the total volume of material to be calculated in $\mathrm{mm}^{3}$. A schematic figure of the volumetric change assessment is illustrated in Figure 1.

Reconstruction of the images was performed with NRecon software (V1.6.4.7; Bruker-MicroCT). The correction parameters for smoothing, beam hardening, and ring artifacts were defined for each material. The same parameters were used for the same material in different periods. The reconstructed images were superimposed on the different periods and saved in the coronal, sagittal, and transaxial planes by using the Data Viewer program (V1.5.2.4; BrukerMicroCT). The images were analyzed with CTAn software (V1.11.8; Bruker-MicroCT). The volume filled by the sealers was calculated at each time interval. A 3-dimensional model of the filled cavities was obtained by using the CTVol software (V2.0; Bruker-MicroCT) (Fig. 2).

\section{Statistical Analysis}

Preliminary data analysis was performed with the Shapiro-Wilk test. Statistical analysis was performed with parametric tests. The anal- ysis of variance and Tukey comparison tests were used. The level of significance was set at $P<.05$.

\section{Results}

The results are represented in Tables 2 and 3. GFB presented shorter ST $(30$ minutes) and TFBC the highest value $(P<.05)$ (Table 2). GFB presented the lowest radiopacity value $(3.9 \mathrm{~mm} \mathrm{Al})$ in comparison with the other sealers $(P<.05)$, and AHP, the highest value $(9.42 \mathrm{~mm} \mathrm{Al})$.

The solubility value was higher for TFBC when compared with those of the other materials $(P<.05)$ and AHP, the lowest value (Table 2). The $\mathrm{pH}$ was higher for TFBC, followed by GFB, in the whole experimental period (Table 3). GFB presented the lowest flow values $(P<.05)$ in comparison with the other sealers. No statistically significant difference between the root canal sealers in both time intervals was observed for volumetric change test $(P>.05)$.

\section{Discussion}

Standardized tests for evaluating the physicochemical properties of endodontic sealers have been recommended by ISO/ADA $(1,2)$. Carvalho-Junior et al (24) proposed specimens with smaller dimensions for the solubility test, without affecting the accuracy of the methodology. The solubility of root canal sealers is evaluated by the difference in the material mass before and after immersion in distilled

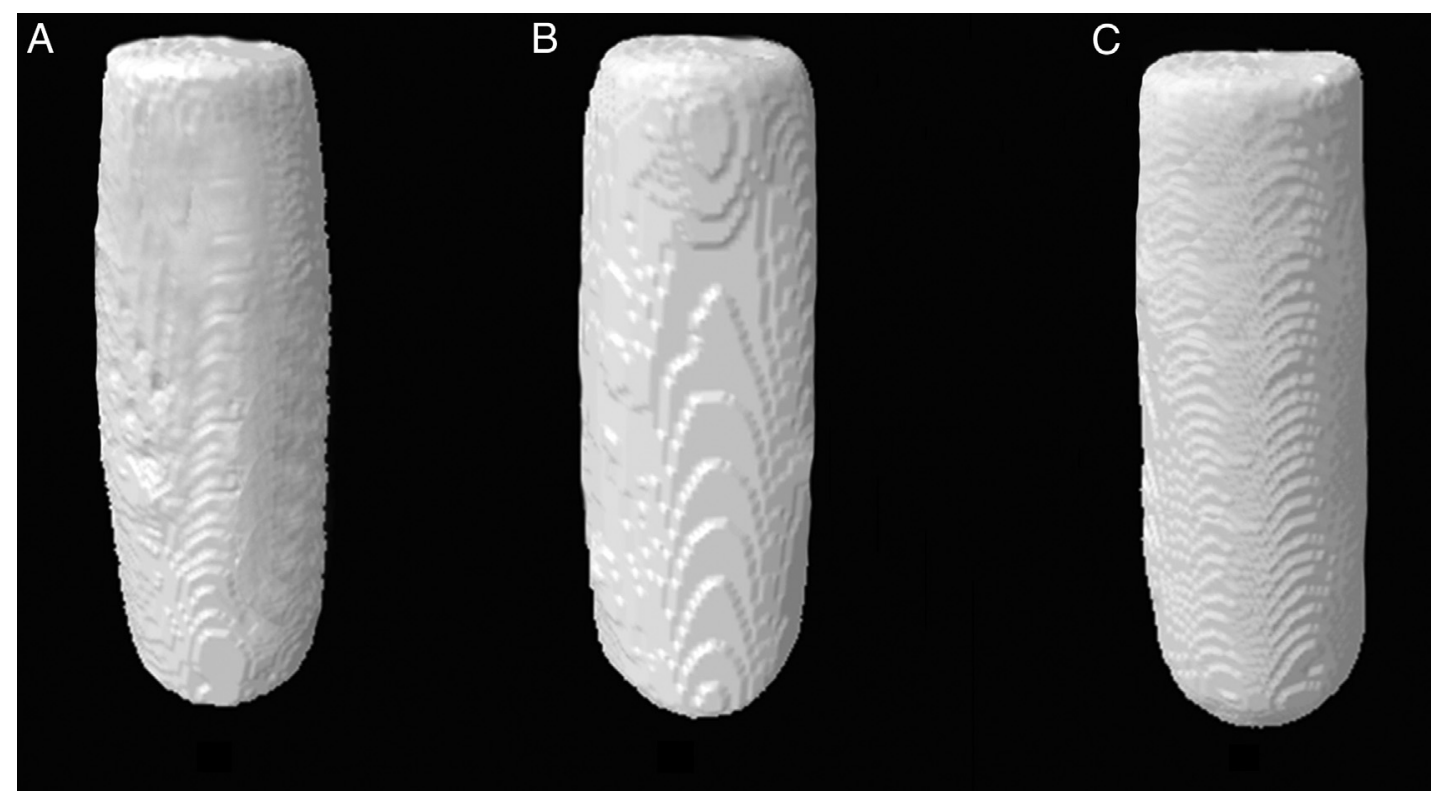

Figure 2. Models after cavity filling with the sealers $(A)$ AH Plus, $(B)$ TotalFill BC Sealer, and $(C)$ GuttaFlow Bioseal reconstructed in 3 dimensions using CTVol software. 
TABLE 2. Setting Time, Radiopacity, Solubility, Flow, and Volumetric Change Values (Mean and Standard Deviation)

\begin{tabular}{|c|c|c|c|}
\hline Tests/Materials & AH Plus & Total Fill BC Sealer & GuttaFlow Bioseal \\
\hline Setting time, min & $384( \pm 0.0)^{b}$ & $581.5( \pm 27.18)^{a}$ & $30.67( \pm 0,82)^{c}$ \\
\hline Radiopacity, mm Al & $9.42( \pm 0.39)^{a}$ & $6.15( \pm 0.39)^{\mathrm{b}}$ & $3.94( \pm 0.21)^{c}$ \\
\hline Solubility 7 days, $\%$ mass loss & $0.041( \pm 0.05)^{c}$ & $7.444( \pm 0.86)^{a}$ & $2.938( \pm 0.45)^{b}$ \\
\hline Solubility $30 \mathrm{~d}, \%$ mass loss & $0.406( \pm 0.27)^{c}$ & $13.49( \pm 0.71)^{a}$ & $4.812( \pm 1.22)^{b}$ \\
\hline Flow, $\mathrm{mm}$ & $21.41( \pm 1.14)^{b}$ & $24.83( \pm 0.79)^{a}$ & $16.88( \pm 0,40)^{c}$ \\
\hline Flow, $\mathrm{mm}^{2}$ & $407.2( \pm 114.2)^{b}$ & $535.4( \pm 52.75)^{a}$ & $240.8( \pm 11.52)^{c}$ \\
\hline Volumetric change $7 \mathrm{~d}, \%$ & $0.50( \pm 0.46)^{a}$ & $0.62( \pm 0.32)^{a}$ & $0.14( \pm 1.06)^{a}$ \\
\hline Volumetric change $30 \mathrm{~d}, \%$ & $-0.19( \pm 0.93)^{a}$ & $-1.07( \pm 0.51)^{a}$ & $-0.68( \pm 0.94)^{a}$ \\
\hline
\end{tabular}

$\mathrm{mm}$ Al, aluminum millimeter; \% mass loss, percentage of mass loss.

a,b,c Different letters in the same row showed statistically significant difference.

water. This test has limitations, because materials may present degradation during storage or absorb water (22). Therefore, the use of microCT may complement conventional tests, providing additional data about volumetric changes in materials (19-21).

According to the present study, GFB demonstrated shorter ST than TFBC and AHP sealers, in agreement with Gandolfi et al (15), who suggested that the presence of calcium silicate in GFB reduced its ST when compared with GuttaFlow. TFBC sealer showed the longest ST.

The radiopacity of all the sealers showed values in accordance with ISO. AHP was the most radiopaque sealer, followed by TFBC and GFB. The differences in radiopacity of the root canal sealers evaluated may be related to the presence of radiopacifying agents in each material (25). These agents have the following decreasing order of radiopacity: bismuth oxide, zirconium oxide, calcium tungstate, barium sulphate, and zinc oxide (26). The quantity and proportion of each radiopacifying agent may interfere in the radiopacity of the cements. Therefore, the presence of calcium tungstate in addition to the zirconium oxide in the AHP cement provided the material with higher radiopacity (25), whereas TFBC and GFB presented only zirconium oxide in their composition.

Calcium silicate cements provide an alkaline $\mathrm{pH}$, as a result of calcium ion release (15). TFBC demonstrated the highest $\mathrm{pH}$ values, as observed by Zhou et al (10) for the EndoSequence BC Sealer. GFB was the sealer with the second highest $\mathrm{pH}$ value, which may have occurred as a result of its capacity for forming hydroxyapatite due to the presence of bioactive ceramic glass, in spite of its low calcium release values (15). The alkalinity demonstrated may contribute to the osteogenic potential, biocompatibility, and antibacterial capacity of this material (10). Furthermore, it has been suggested that the mechanism of mineralized tissue repair depends on the $\mathrm{pH}$ and capacity for releasing $\mathrm{Ca}^{2+}$ of the material (27).

Higher solubility was observed for the TFBC that showed high calcium ion (15) and hydroxyl release values. The lowest values were observed for AHP, which may be related to the crossed links in its resin polymers (28) that promoted low solubility (29).

Volumetric change of the material after immersion in distilled water may be observed by using micro-CT. Cavenago et al (19) evaluated MTA with different powder-water ratios and associated the loss of volume with the solubility of the material. The solubility of materials cannot be related exclusively to the volumetric behavior, particularly for calcium silicate-based cements that may absorb water (21). Therefore, Torres et al (21) evaluated the volumetric change in reparative cements after setting and immersion in distilled water for time intervals of 7 and 30 days. Silva et al (20) used the volumetric change test to observe the behavior of root canal sealers after immersion in PBS solution for 7 days.

The results of the present study demonstrated similar volumetric change values for all the sealers studied, differently from that which occurred in the conventional solubility test, when TFBC was the material that showed the highest loss of mass values and AHP, the lowest. Therefore, we must consider that volumetric changes do not depend on the solubility of cements only, but also on dimensional changes such as contraction or expansion $(20,21)$. Gandolfi et al (15) observed low solubility and high water sorption for GFB, suggesting that the material may exhibit expansion and mass loss. So, the solubility of this sealer after 7 days could be compensated by the fluid absorption (3), resulting a volume increase. After 30 days, we observed volumetric reduction probably because the solubility was higher than water absorption. Similarly, the higher solubility of TFBC in the conventional solubility test may have been compensated by the absorption of fluids that occurred in calcium silicate-based cements, resulting in their volumetric stability (20). The volumetric change test must be considered an additional test to the solubility test and present correlation with its clinical performance.

Previous studies have observed that TFBC showed high bond strength values in the push-out test $(12,13)$, which suggested that the calcium silicate-based sealers provide good adaptation to dentin (14). The good penetrability of these materials may be explained as being due to the reduced size of its cement particles (30) and probably due to the adequate flow values that were observed in the present study.

In conclusion, TFBC sealer presented the highest ST, pH, solubility, and flow values, in addition to similar volumetric change to that of the other sealers studied. GFB showed adequate physicochemical properties. Micro-CT can complement conventional tests, allowing better knowledge of the behavior of materials, and improving its clinical application.

TABLE 3. $\mathrm{pH}$ Values (Mean and Standard Deviation) at the Different Experimental Periods

\begin{tabular}{lcccc}
\hline Experimental periods & AH Plus & Total Fill BC & GuttaFlow Bioseal & Control \\
\hline 1 day & $6.583( \pm 0.16)^{c}$ & $10.37( \pm 0.20)^{\mathrm{a}}$ & $8.203( \pm 0.46)^{\mathrm{b}}$ & $6.480( \pm 0.27)^{\mathrm{c}}$ \\
3 days & $6.589( \pm 0.22)^{\mathrm{c}}$ & $10.61( \pm 0.16)^{\mathrm{a}}$ & $8.202( \pm 0.49)^{\mathrm{b}}$ & $6.422( \pm 0.23)^{\mathrm{c}}$ \\
7 days & $5.957( \pm 0.22)^{\mathrm{c}}$ & $10.29( \pm 0.21)^{\mathrm{a}}$ & $8.512( \pm 0.25)^{\mathrm{b}}$ & $6.248( \pm 0.10)^{\mathrm{c}}$ \\
14 days & $6.428( \pm 0.43)^{\mathrm{c}}$ & $10.53( \pm 0.14)^{\mathrm{a}}$ & $7.573( \pm 0.14)^{\mathrm{b}}$ & $6.200( \pm 0.12)^{\mathrm{c}}$ \\
21 days & $6.040( \pm 0.20)^{\mathrm{c}}$ & $9.500( \pm 0.93)^{\mathrm{a}}$ & $7.388( \pm 0.14)^{\mathrm{b}}$ & $6.368( \pm 0.23)^{\mathrm{c}}$ \\
28 days & $5.672( \pm 0.25)^{\mathrm{c}}$ & $9.213( \pm 0.86)^{\mathrm{a}}$ & $7.238( \pm 0.29)^{\mathrm{b}}$ & $6.320( \pm 0.22)^{\mathrm{c}}$ \\
\hline
\end{tabular}

Control, distilled water.

${ }^{a, b, c}$ Different letters in the same row showed statistically significant difference. 


\section{Acknowledgments}

The authors thank Renato Luiz Carvalho for bis assistance with the illustrations.

This work was supported by FAPESP (2015/03437-6 and 2016/ 00321-0).

The authors deny any conflicts of interest related to this study.

\section{References}

1. American National Standards Institute/American Dental Association (ANSI/ADA) Specification no. 57 ADA. Laboratory Testing Methods: Endodontic Filling and Sealing Materials. Endodontic Sealing Materials. Chicago, IL: ANSI/ADA; 2000.

2. International Organization for Standardization Dentistry (ISO). ISO 6876. Root Canal Sealing Materials. London, UK: British Standards Institution; 2002.

3. Silva Almeida LH, Moraes RR, Morgental RD, et al. Are premixed calcium silicatebased endodontic sealers comparable to conventional materials? A systematic review of in vitro studies. J Endod 2017;43:527-35.

4. Akcay M, Arslan H, Durmus N, et al. Dentinal tubule penetration of AH Plus, iRoot SP, MTA fillapex, and guttaflow bioseal root canal sealers after different final irrigation procedures: a confocal microscopic study. Lasers Surg Med 2016;48:70-6.

5. Borges AH, Orcati Dorileo MC, Dalla Villa R, et al. Physicochemical properties and surfaces morphologies evaluation of MTA FillApex and AH plus. ScientificWorldJournal 2014;2014:589732.

6. Garrido AD, Lia RC, Franca SC, et al. Laboratory evaluation of the physicochemical properties of a new root canal sealer based on Copaifera multijuga oil-resin. Int Endod J 2010;43:283-91.

7. Marciano MA, Guimaraes BM, Ordinola-Zapata R, et al. Physical properties and interfacial adaptation of three epoxy resin-based sealers. J Endod 2011;37:1417-21.

8. Marin-Bauza GA, Rached-Junior FJ, Souza-Gabriel AE, et al. Physicochemical properties of methacrylate resin-based root canal sealers. J Endod 2010;36:1531-6.

9. Hess D, Solomon E, Spears R, et al. Retreatability of a bioceramic root canal sealing material. J Endod 2011;37:1547-9.

10. Zhou HM, Shen Y, Zheng W, et al. Physical properties of 5 root canal sealers. J Endod 2013;39:1281-6.

11. Rodriguez-Lozano FJ, Garcia-Bernal D, Onate-Sanchez RE, et al. Evaluation of cytocompatibility of calcium silicate-based endodontic sealers and their effects on the biological responses of mesenchymal dental stem cells. Int Endod J 2017;50:67-76.

12. Carvalho NK, Prado MC, Senna PM, et al. Do smear-layer removal agents affect the push-out bond strength of calcium-silicate based endodontic sealers? Int Endod J 2017;50:612-9.

13. Gokturk H, Bayram E, Bayram HM, et al. Effect of double antibiotic and calcium hydroxide pastes on dislodgement resistance of an epoxy resin-based and two calcium silicate-based root canal sealers. Clin Oral Investig 2017;21:1277-82.
14. Agrafioti A, Koursoumis AD, Kontakiotis EG. Re-establishing apical patency after obturation with gutta-percha and two novel calcium silicate-based sealers. Eur J Dent 2015;9:457-61.

15. Gandolfi MG, Siboni F, Prati C. Properties of a novel polysiloxane-guttapercha calcium silicate-bioglass-containing root canal sealer. Dent Mater 2016;32:e113-26.

16. Collado-Gonzalez M, Tomas-Catala CJ, Onate-Sanchez RE, et al. Cytotoxicity of GuttaFlow Bioseal, GuttaFlow2, MTA Fillapex, and AH Plus on human periodontal ligament stem cells. J Endod 2017;43:816-22.

17. Nielsen RB, Alyassin AM, Peters DD, et al. Microcomputed tomography: an advanced system for detailed endodontic research. J Endod 1995;21:561-8.

18. Rhodes JS, Ford TR, Lynch JA, et al. Micro-computed tomography: a new tool for experimental endodontology. Int Endod J 1999;32:165-70.

19. Cavenago BC, Pereira TC, Duarte MA, et al. Influence of powder-to-water ratio on radiopacity, setting time, $\mathrm{pH}$, calcium ion release and a micro-CT volumetric solubility of white mineral trioxide aggregate. Int Endod J 2014;47:120-6.

20. Silva EJ, Perez R, Valentim RM, et al. Dissolution, dislocation and dimensional changes of endodontic sealers after a solubility challenge: a micro-CT approach. Int Endod J 2017;50:407-14.

21. Torres FFE, Bosso-Martelo R, Espir CG, et al. Methods using micro-CT for evaluating physicochemical properties and volumetric changes in root-end filling materials. J Appl Oral Sci 2017;25:374-80.

22. Parirokh M, Torabinejad M. Mineral trioxide aggregate: a comprehensive literature review-Part I: chemical, physical, and antibacterial properties. J Endod 2010;36:16-27.

23. Tanomaru-Filho M, Silveira GF, Tanomaru JM, et al. Evaluation of the thermoplasticity of different gutta-percha cones and Resilon. Aust Endod J 2007:33:23-6.

24. Carvalho-Junior JR, Correr-Sobrinho L, Correr AB, et al. Solubility and dimensional change after setting of root canal sealers: a proposal for smaller dimensions of test samples. J Endod 2007;33:1110-6.

25. Candeiro GT, Correia FC, Duarte MA, et al. Evaluation of radiopacity, pH, release of calcium ions, and flow of a bioceramic root canal sealer. J Endod 2012;38:842-5.

26. Hungaro Duarte MA, de Oliveira El Kadre GD, Vivan RR, et al. Radiopacity of portland cement associated with different radiopacifying agents. J Endod 2009;35: $737-40$.

27. Okabe T, Sakamoto M, Takeuchi H, et al. Effects of $\mathrm{pH}$ on mineralization ability of human dental pulp cells. J Endod 2006;32:198-201.

28. Borges RP, Sousa-Neto MD, Versiani MA, et al. Changes in the surface of four calcium silicate-containing endodontic materials and an epoxy resin-based sealer after a solubility test. Int Endod J 2012;45:419-28.

29. Viapiana R, Flumignan DL, Guerreiro-Tanomaru JM, et al. Physicochemical and mechanical properties of zirconium oxide and niobium oxide modified Portland cement-based experimental endodontic sealers. Int Endod J 2014;47:437-48.

30. McMichael GE, Primus CM, Opperman LA. Dentinal tubule penetration of tricalcium silicate sealers. J Endod 2016;42:632-6. 